\title{
Prophylactic use of antibiotics and immunisations in patients with SLE
}

\section{W R Gilliland, G C Tsokos}

\section{Early diagnosis and treatment of infections in SLE is a challenge}

O ver the past several decades, medical research has improved our knowledge about the cause, recognition, and treatment of a variety of infectious diseases. Despite these advances, infections remain a major cause of morbidity and mortality in patients with systemic lupus erythematosus (SLE) throughout the world..$^{1-3}$ Almost two decades ago, the Lupus Survival Study Group examined the causes of death of 1103 patients with SLE. Infections accounted for $33 \%$ of the deaths, whereas active disease for $31 \%{ }^{4}$ Table 1 summarises more recent studies, demonstrating the discouraging fact that the percentage of deaths due to infection has changed little since the earlier reports.

Doctors caring for patients with SLE are left to answer the vexing question: how do we control the inflammation related to disease activity without increasing the infection rate? Considering that corticosteroids and other immunosuppressive agents used to control the underlying disease also increase the susceptibility to infections, this is indeed a difficult question.

\section{POSSIBLE STRATEGIES}

Several strategies may be helpful in decreasing the morbidity and mortality related to infections.

\section{Simple hygiene}

Perhaps the simplest strategy is to educate patients and their healthcare providers about the importance of simple hygienic measures such as hand washing in order to reduce the transmission of common infectious agents. In addition, when possible, it is important to limit exposure to people with communicable illnesses.

\section{Use of antimicrobial agents}

The second important strategy is the prophylactic use of antimicrobial agents. In this issue of the Annals of the Rheumatic Diseases, Gaitonde and colleagues report their results with isoniazid (INH) prophylaxis in a group of patients with SLE in India. ${ }^{8}$ INH was started in all patients with SLE who were treated with "long term" corticosteroids. When compared with a similar historical cohort from some of the same researchers, the incidence of tuberculosis decreased from $11 \%$ to $2 \%{ }^{8}{ }^{9}$

This study had several limitations. One obvious limitation is the lack of generalisability of the benefit of INH prophylaxis in areas in which the prevalence of tuberculosis differs. In geographical areas such as the Philippines where the reported prevalence of tuberculosis in a cohort of patients with SLE was $13.7 \%{ }^{10}$ or in Vietnam with a prevalence of $27 \%$ of clinical tuberculosis, ${ }^{11}$ a similar strategy may be entertained. Obviously, in other areas with a high prevalence of tuberculosis, prophylaxis may also be very beneficial. On the other hand another study of 451 Greek patients with a variety of connective tissue disorders, including SLE, recommended that purified protein derivative screening with INH prophylaxis may not be necessary in patients with rheumatic syndromes who are receiving corticosteroids because of the low prevalence of tuberculosis in that cohort of patients. ${ }^{12}$
While there are only isolated cases of tuberculosis in patients with SLE in Western countries, tuberculosis is considered to be a growing public health hazard, especially in areas with a high prevalence of AIDS. ${ }^{13}$ Although prophylaxis with INH is not commonly practised, it is currently recommended in patients with positive tuberculin skin tests requiring high dose prednisone for SLE and other diseases. ${ }^{14}$ Risk factors for developing tuberculosis in patients with rheumatic diseases include the cumulative and mean daily dose of corticosteroids and a history of pulse corticosteroids treatment. ${ }^{15}$

A second limitation of the study by Gaitonde and colleagues is the lack of monitoring for liver toxicity in those patients who had no clinical symptoms suggestive of liver toxicity. ${ }^{8}$ With estimates of increased liver enzymes in 17\% of patients taking isoniazid ${ }^{16}$ and the potential for progressive liver damage, this strategy of INH prophylaxis would not be acceptable in most Western countries.

\section{"Infections are a major cause of mortality in SLE"}

Obviously, the agents one considers using for prophylaxis are dependent on the prevalence of specific diseases in that particular group of patients. While prophylaxis against tuberculosis in Western countries may not be as much of a public health issue as in India, prophylaxis against a variety of other infectious agents is commonplace. Once previously thought to be unique to patients with AIDS, Pneumocystis carinii is being increasingly recognised in patients with SLE and other inflammatory disorders. ${ }^{17}$ Most patients who developed Pneumocystis carinii pneumonia were receiving corticosteroids and other cytotoxic agents and were lymphopenic at the time of their diagnosis. ${ }^{18}$ Strategies using a regimen of low dose trimethaprim/ sulfamethoxazole three times weekly, or inhaled pentamidine monthly, should be considered in selected patients with active SLE being treated with immunosuppressive agents. ${ }^{18} 19$

\begin{tabular}{|c|c|c|c|c|}
\hline Author & Years covered & Patients (n) & Deaths (n) & $\begin{array}{l}\text { Infection as } \\
\text { primary cause of } \\
\text { death (No (\%)) }\end{array}$ \\
\hline Harvey ef al, $1954^{5}$ & $1949-54$ & 138 & 38 & $15(39)$ \\
\hline Ginzler et al, $1978^{\circ}$ & $1966-76$ & 223 & 55 & $20(36)$ \\
\hline Rosner et al, $1982^{4}$ & $1965-78$ & 1103 & 222 & $74(33)$ \\
\hline Pistiner et al, $1991^{2}$ & 1980-89 & 464 & 26 & $5(19)$ \\
\hline Janwityanuchit et al, 19937 & $1980-89$ & 537 & 77 & $23(30)$ \\
\hline Nossent, $1993^{3}$ & $1980-90$ & 68 & 22 & $11(50)$ \\
\hline
\end{tabular}


Certainly, patients with SLE who have valvular abnormalities should receive endocarditis prophylaxis before invasive dental or genitourinary procedures. ${ }^{20}$ Although controversial, others have argued that because of the high percentage of patients with SLE who have endothelial damage to the heart valves (as high as $50 \%$ ) in patients with SLE, antibiotic treatment should be considered in all patients with SLE who are undergoing procedures associated with transient bacteraemia in accordance with standard regimens suggested by the American Heart Association. ${ }^{21}$

\section{Immunisations}

The third important preventive measure is through the use of immunisations. Initially, there were reports of impaired immune response to pneumococcal vaccinations in patients with $\mathrm{SLE}_{,}{ }^{22}$ but more recent studies suggest that vaccinations are generally safe and effective. ${ }^{23}$ Furthermore, antigenicity of the pneumococcus was not affected by concomitant immunosuppressive treatment. ${ }^{24}$

\section{"Pneumocystis carinii is increasingly found in patients with SLE"}

For influenza vaccines, no differences in antibody response and safety were found when a group of healthy people were compared with patients with SLE. ${ }^{25}$ A more recent study concluded that a protective immune response can be achieved safely in patients with SLE with both tetanus toxoid and Haemophilus influenzae type $\mathrm{B}$ in addition to pneumococcus. ${ }^{23}$ Although vaccination in patients with SLE is felt to be safe, the presumed role of vaccine induced polyclonal B cell activation in causing or exacerbating rheumatic disease is unknown. Rheumatic syndromes temporally related to vaccination, especially hepatitis B, have been described, but a casual relationship has not been established. ${ }^{26} 27$

\section{SUMMARY}

Infections remain a serious and important cause of morbidity and mortality in patients with SLE. ${ }^{28}$ Early diagnosis and treatment of infections in lupus patients is, and will remain, one of the most difficult challenges for doctors. Strategies to decrease the impact of these infections include:
- Simple hygienic measures and education aimed at both patients and doctors

- Antimicrobial prophylaxis in cohorts of patients with increased prevalence of certain infections, patients who receive heavy doses of immunosuppressive agents, or undergo procedures associated with temporary bacteraemia

- Immunisations similar to those available to the general population.

Ann Rheum Dis 2002;61:191-192

\section{Authors' affiliations}

W R Gilliland, G C Tsokos, Department of

Medicine, Uniformed Services University of the Health Sciences, 4301 Jones Bridge Road, Bethesda, MD 20814, USA

Correspondence to Dr W R Gilliland wgilliland@usuhs.mil and gtsokos@usuhs.mil

\section{REFERENCES}

1 Massardo R, Martinez ME, Jacobelli S, Villarroel L, Rosenberg H, Rivero S. Survival of Chilean patients with systemic lupus erythematosus. Semin Arthritis Rheum 1994:24:1-11.

2 Pistiner M, Wallace DJ, Nessim S, Metzger AL, Klinenberg JR. Lupus erythematosus in the 1980s: a survey of 570 patients. Semin Arthritis Rheum 1991;21:55-64.

3 Nossent JC. Course and prognostic value of systemic lupus activity index in black Caribbean patients. Semin Arthritis Rheum 1993;23:16-21.

4 Rosner S, Ginzler EM, Diamond HS, Weiner $M$, Schlesinger $M$, Fries JF, et al. A multicenter study of outcome in systemic lupus erythematosus: II. Causes of death. Arthritis Rheum 1982;25:612-17.

5 Harvey AM, Shulman LE, Kaplan D. Systemic lupus erythematosus: review of the literature and clinical analysis of 138 cases. Medicine (Baltimore) 1954;33:291-437.

6 Ginzler E, Diamond H, Kaplan D, Weiner M, Schlesinger $M$, Seleznick. Computer analysis of factors influencing frequency of infection in systemic lupus erythematosus. Arthritis Rheum 1978;21:37-44.

7 Janwityanuchit S, Totemchokchyakarn K, Krachangwongchai K, Vatanasuk M. Infection in systemic lupus erythematosus. J Med Assoc Thai 1993;76:542-8

8 Gaitonde S, Pathan E, Sule A, Mittal G, Joshi VR. Efficacy of isoniazid prophylaxis in patients with systemic lupus erythematosus receiving long term steroid treatment. Ann Rheum Dis 2002:61:251-3.

9 Balakrishnan C, Mangat G, Mittal G, Joshi VR. Tuberculosis in patients with systemic lupus erythematosus. J Assoc Physicians India 1998:46:682-3.

10 Victtorio-Navarra STG, Arroyo CG, Torralba T. Tuberculosis among Filipino patients with systemic lupus erythematosus. Lupus 1995;4 (suppl 2):89.

11 Phan JC, Bush TM, Donald F, Ward M Clinical and laboratory features of patients of Vietnamese descent with systemic lupus erythematosus. Lupus 1999;8:521-4.

12 Andonopoulos AP, Safridi C, Karokis D, Bounas $A$. Is a purified protein derivative skin test and subsequent antituberculous chemoprophylaxis really necessary in systemic rheumatic disease patients receiving corticosteroids? Clin Rheumatol 1998;17:181-5.

13 Young LS. Mycobacterial diseases and the compromised host. Clin Infect Dis 1993; 17(suppl 2):436-41.

14 American Thoracic Society and Centers for Disease Control. Recommendations: implementation of targeted tuberculin testing. Amer J Respir Crit Care Med 2000;161:S233-41.

15 Kim HA, Yoo CD, Baek HJ, Lee EB, Ahn C, Han JS, et al. Mycobacterium tuberculosis infection in a corticosteroid-treated rheumatic disease patient population. Clin Exp Rheumatol 1998;16:9-13.

16 Stuart RL, Wilson J, Grayson ML. Isoniazid toxicity in health care workers. Clin Infect Dis 1999:28:895-7.

17 Liam CK, Wang F. Pneumocystis carinii pneumonia in patients with systemic lupus erythematosus. Lupus 1992;1:379-85.

18 Porges AJ, Beattie SL, Ritchlin C, Kimberly RP, Christian CL. Patients with systemic lupus erythematosus at risk for Pneumocysitis carinii pneumonia. J Rheumatol 1992;19:1191-4.

19 Sneller MC, Hoffman GS, Talar-Williams C, Kerr GS, Hallahan CW, Fauci AS. An analysis of forty-two Wegener's granulomatosis patients treated with methotrexate and prednisone. Arthritis Rheum 1995:38:608-13.

20 Zysset MK, Montgomery MT, Redding SW, Dell Italia L. Systemic lupus erythematosus: a consideration for anitmicrobial prophylaxis. Oral Surg Oral Med Oral Pathol 1987;64:30-4

21 Dajani AS, Taubert KA, Wilson W, Bolger $\mathrm{AF}$, Bayer A, Ferrieri $\mathrm{P}$, et al. Prevention of bacterial endocarditis. Recommendations by the American Heart Association. JAMA 1997;277: 1794-801.

22 Croft SM, Schiffman G, Snyder E, Herrmann K, James K, Jarrett MP. Specific antibody response after in vivo antigenic stimulation in systemic lupus erythematosus. J Rheumatol 1984;11:141-6

23 Battafarano DF, Battafrano NJ, Larsen L, Dyer PD, Older SA, Muehlbauer S, et al. Antigen-specific antibody responses in lupus patients following immunization. Arthritis Rheum 1998:41:1828-34.

24 Lipnick RN, Karsh J, Stahl NI, Blackwelder WC, Schiffman G, Klippel JH. Pneumococcal immunization in patients with systemic lupus erythematosus treated with immunosuppressives. J Rheumatol 1985;12:1118-21.

25 Herron A, Dettleff G, Hixon B, Brandwin L, Ortals D, Hornick R, et al. Influenza vaccination in patients with rheumatic diseases. Safety and efficacy. JAMA 1979;242:53-6.

26 Maillefert JF, Sibilia J, Toussirot E, Vignon E, Eschard JP, Lorcerie B, et al. Rheumatic disorders developed after hepatitis $B$ vaccination. Rheumatology (Oxford) 1999;38:978-83.

27 Older SA, Battafarano DF, Enzenauer R, Krieg AM. Can immunization precipitate connective tissue disease? Report of five case of systemic lupus erythematosus and review of the literature. Semin Arthritis Rheum 1999;29:131-9.

28 Iliopoulos A, Tsokos GC. Immunopathogenesis of infections in systemic lupus erythematosus. Semin Arthritis Rheum $1996 ; 25: 318-33$ 